\title{
Speciation of the Plague Microbe Yersinia Pestis As a Unique Natural Phenomenon
}

\author{
Victor Suntsov ${ }^{1}$ and Gregory Adler ${ }^{2 *}$ \\ ${ }^{1}$ Institute problems of Ecology and Evolution, Moscow, Russia \\ ${ }^{2}$ University of Wisconsin-Oshkosh, Oshkosh, USA
}

*Corresponding author: Gregory Adler, Department of Biology and Microbiology, University of Wisconsin-Oshkosh, USA

\begin{tabular}{|c|c|}
\hline ARTICLE INFO & ABSTRACT \\
\hline Received: August 18, 2020 & Citation: Victor Suntsov, Gregory Adler. Speciation of the Plague Microbe Yersinia \\
\hline Published: 业 September 02, 2020 & $\begin{array}{l}\text { Pestis As a Unique Natural Phenomenon. Biomed J Sci \& Tech Res 30(1)-2020. BJSTR. } \\
\text { MS.ID.004880. }\end{array}$ \\
\hline
\end{tabular}

\section{Mini Review}

Where, when, and how did the causative agent of plague arise? This issue remains highly relevant at present, as understanding the principle of this apocalyptic infection will contribute to improving the global system of human infection security. The genus Yersinia belongs to the gram-negative bacteria of the family Enterobacteriaceae. It includes three well-studied species of human pathogens: the enteropathogenic Yersinia pseudotuberculosis and $Y$. enterocolitica and the systemic plague pathogen Y. pestis. In nature, Y. pseudotuberculosis has a nearly global distribution and causes a mild gastrointestinal infection (pseudotuberculosis) in a wide range of invertebrate and vertebrate animal hosts; the infection passes alimentarily, as hosts are infected by oral routes. Yersinia enterocolitica also causes gastrointestinal infections (yersiniosis). Yersinia pestis causes systemic ("blood") infections mainly in populations of burrowing rodents, is transmitted through flea bites and forms territorially organized natural plague foci. Thus, the bacteria Y. pseudotuberculosis (and the similar Y. enterocolitica) and $Y$. pestis have radically different habitats and therefore occupy dramatically different ecological niches and adaptive zones.

In the last two decades, molecular genetic (MG) methods have revealed that the direct ancestor of the plague pathogen is the psychorophilic causative agent of pseudotuberulosis, which is widespread in cold areas of northern Asia. Specifically, the ancestor is the 1st serotype Y. pseudotuberculosis 0:1b, and the two species diverged no more than 30,000 years ago [1,2]. The recent conversion of a particular clone of a pseudotuberculosis microbe into a population of the plague pathogen is considered to be a population-genetic process of macro-evolutionary scale, as the plague microbe is not an intestinal inhabitant, and it should not be included in the Enterobacteriaceae family [3]. At the same time, in the family Enterobacteriaceae and in the genus Yersinia, the plague pathogen is a unique representative. This means that $Y$. pestis originated under some unique environmental conditions. What happened in Asia in the relatively recent past that led to the emergence of such an unusual and dangerous microbe? How did the pseudotuberculosis microbe change its original habitat in the intestinal tract of various animals to circulation in the rodent-flea system?

The new environmental and MG data accumulated to date provide what we believe is a definitive answer to this question: the uniqueness of $Y$. pestis is the non-adaptive traumatic initial penetration of the pseudotuberculosis microbe into the lymphmyeloid complex of the primary host, the Mongolian or tarbagan marmot (Marmota sibirica). Non-specialized traumatic "entry gates" of pseudotuberculosis infection in the lympho-myeloid complex of marmots arose due to a combination of environmental circumstances in an area with a severe ultra-continental climate - Central Asia (Mongolia) at the boundary of the Pleistocene and Holocene. This period of geological history of the Earth and the evolution of the Earth's biota is characterized by the last maximum (Sartan) cooling of the climate in northern Asia and deep freezing of the ground up to the southern border of Mongolia [4]. Deep freezing of soil in the range of the Mongolian marmot led to a change in the behavior of larvae of the flea Oropsylla silantiewi, specifically 
the emergence of the phenomenon of larval hematophagy. Due to positive thermotaxis, flea larvae in the winter months began to move en mass from the freezing nest lining in the burrows of hibernating family groups of marmots to the warmer marmot bodies, thereby creating wounds (scarifications) on the skin and available mucous membranes, particularly in the oral cavity of the dormant marmots [5].

Long before the maximum Sartan cooling reached Central Asia, the Mongolian marmot, which lives in semi-arid steppe and montanesteppe landscapes, has formed a species-specific behavior; unlike other species of marmots, the Mongolian marmot makes a burrow plug from a mixture of rubble and its own feces, which serves as a binding material for the plug. During plug fabrication, feces enters the mouth of marmots, and the pseudotuberculosis microbe enters the bloodstream of marmots via the scarifications caused by the larval fleas. Thus, there is an initial traumatic "blood contamination" of hibernating marmots, followed by septicaemia. The traumatic pathway of mass infection by pseudotuberculosis in populations of the primary host of the plague microbe (the Mongolian marmot) is the central ecological tenet for understanding the mechanism of the origin of the plague microbe. Major transformations on the macroevolutionary scale differ from the small, fundamental genetic changes that are directional and largely irreversible, and this is the most important role that isolation plays in this system. Due to environmental refugia in the Central Asian biogeocenosis, the microbial cells of the causative agent of pseudotuberculosis acquired a stable ability to enter the bloodstream of hibernating marmots in a traumatic way, while the reverse route from the blood to the source of infection (to the material of the plug of the winter burrow) did not occur (Figure 1).

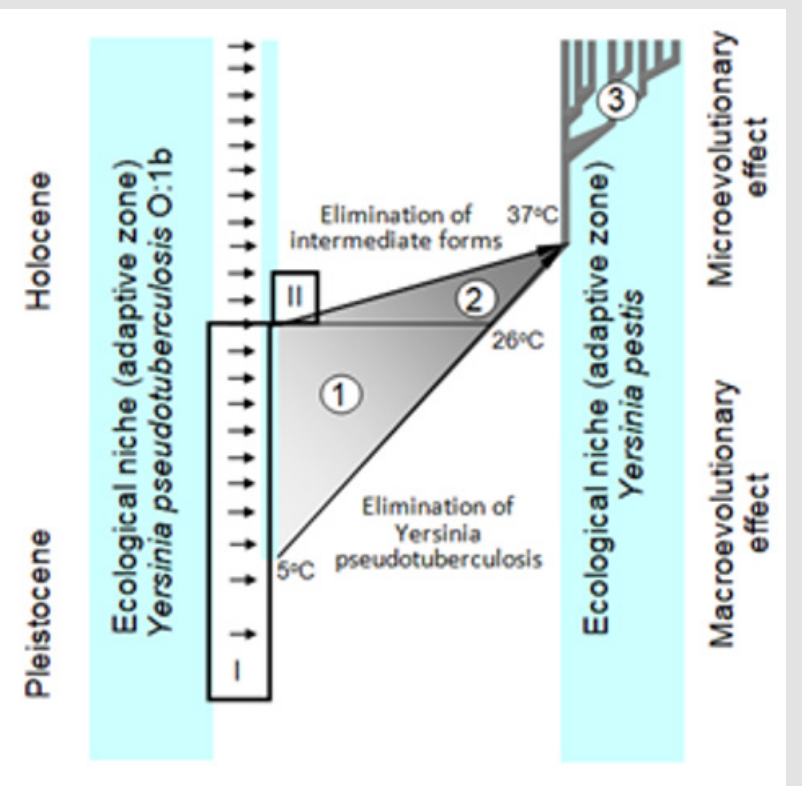

Figure 1.
(Figure 1) A sequence of stages of population-genetic transformations in the origin of Yersinia pestis. I - spatialenvironmental isolation: the unidirectional transfer of microbial cells Yersinia pseudotuberculosis from the fecal components of burrow "plug" into the blood of hibernating marmots. II biochemical (genetic) isolation in the transitional population: the synthesis of pesticine, the emergence of interspecies hiatus. 1 - increasing of polymorphism. 2 - species specialization. 3 adaptive radiation. Due to the complete isolation of clones of the pseudotuberculosis microbe, which penetrated directly into the blood of Mongolian marmots, a unique flow of genes occurred, and the natural selection of microbial cells in novel unique conditions led to the origin of a new species, Y. pestis. A crucial factor in the $Y$. pestis speciation process is the synthesis of pesticin bacteriocin, an apomorphous trait of the plague microbe. Pesticin inhibits the growth of the ancestral pseudotuberculosis microbe and cells of the plague microbe that do not synthesize pesticin and thus provides population homogeneity and species stability of $Y$. pestis.

The synthesis of pesticin by the plague microbe initiated a new system of chemical interactions in the microbial populations. It became an isolating factor that created a reliable distinction between the ancestral pseudotuberculosis microbe and the daughter plague microbe, which irrevocably divided these two species. Modern MG methods applied to the plague microbe revealed its genetic relationship to the pseudotuberculosis microbe but could not reveal the unique environmental conditions that promoted the evolutionary divergence of the plague microbe. Such methods therefore did not provide a plausible scenario of the conversion of the clone Y. pseudotuberculosis 0:1b into the population of $Y$. pestis. Rather, a synthesis of modern MG and ecological methods allowed us to develop a plausible scenario for the evolution of the plague microbe $[6,7]$.

\section{References}

1. Skurnik M, Peippo A, Ervela E (2000) Characterization of the O-Antigen Gene Cluster of Yersinia pseudotuberculosis and the Cryptic 0-Antigen Gene Cluster of Yersinia pestis Shows That the Plague Bacillus Is Most Closely Related to and Has Evolved from Y. pseudotuberculosis Serotype 0:1b Mol Microbiol 37(2): 316-330.

2. Morelli G, Song Y, Mazzoni CJ, Mark Eppinger, Philippe Roumagnac, et al. (2010) Yersinia pestis genome sequencing identifies patterns of global phylo genetic diversity. Nat Genet 42(12): 1140-1143.

3. Suntsov VV (2012) Origin of the Plague Microbe Yersinia pestis: Structure of the Process of Speciation. Biol Bull 39(1): 1-9.

4. Owen LA, Richards B, Rhodes EJ, W Dickson Cunningham, Brian F Windley, et al. (1998) Relict Permafrost Structures in the Gobi of Mongolia: Age and Significance. J Quater Sci 13(6): 539- 547.

5. Suntsov VV, Suntsova NI (2000) Ecological Aspects of Evolution of the Plague Microbe Yersinia pestis and the Genesis of Natural Foci. Biol Bull 27(6): 541-552.

6. Suntsov VV (2019) Origin of the Plague: Prospects of EcologicalMolecular-Genetic Synthesis. Herald Rus Acad Sci 89(3): 271-278.

7. Suntsov VV (2020) Prospects for the Synthesis of Ecological and Molecular-Genetic Approaches to the Problem of the Speciation of the Plague Microbe Yersinia pestis. Biol Bull Rev 10(4): 324-337. 
ISSN: 2574-1241

DOI: 10.26717/BJSTR.2020.30.004880

Gregory Adler. Biomed J Sci \& Tech Res

(C) This work is licensed under Creative

Submission Link: https://biomedres.us/submit-manuscript.php

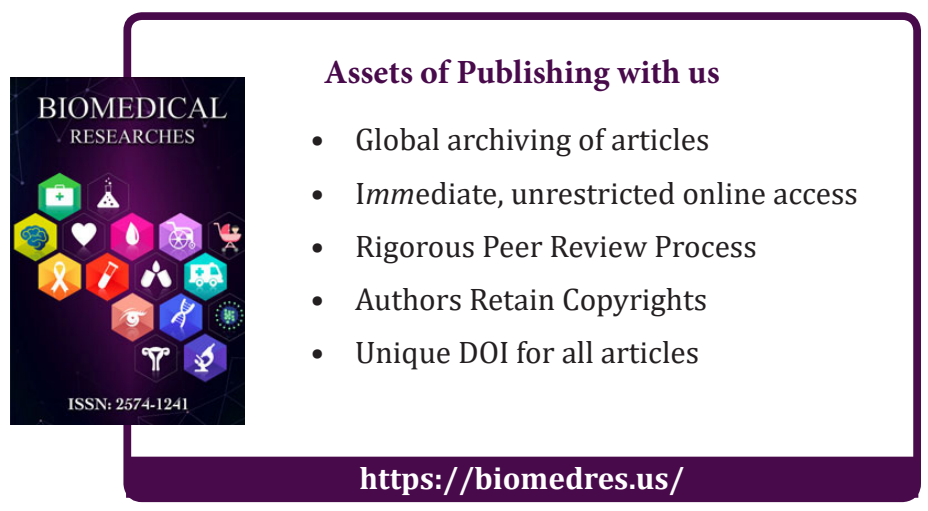

